\title{
LIGHTWEIGHT MANUFACTURING PREDICTION FOR AUTOMOTIVE INDUSTRY
}

\author{
Tatiane Wadas \\ PhD student, Sályi István Doctoral School, University of Miskolc \\ 3515 Miskolc, Miskolc-Egyetemváros, e-mail: metwadas@uni-miskolc.hu \\ Miklós Tisza \\ professor emeritus, Department of Materials Science and Engineering, University of Miskolc \\ 3515 Miskolc, Miskolc-Egyetemváros, e-mail: tisza.miklos@uni-miskolc.hu
}

\begin{abstract}
In this paper, some recent developments in materials applied in sheet metal forming processes with particular interest on the automotive industry will be overviewed. The contradictory demands on these developments will be also summarized. Better performance with lower consumption and lower harmful emission, more safety and comfort are hardly available simultaneously with conventional materials and conventional manufacturing processes. These requirements are the main factors, which support the continuous material and technological developments in sheet metal forming.
\end{abstract}

Keywords: advanced materials, high strength steels, light alloys, sheet metal forming

\section{Introduction}

The automotive industry is always a key industry for sheet metal forming. Therefore, the requirements imposed on the automotive industry are also decisive for sheet metal forming. The automotive industry has recently faced contradictory requirements, such as; lower performance, lower fuel consumption, lower emissions, higher comfort and increased safety are basic requirements that are not or only partially met by conventional materials. Meeting these requirements is the biggest challenge and driving force for the automotive industry and for sheet metal forming. One of the most important ways to meet these versatile requirements is to use the principles and methods of weight reduction and safety requirements [4].

The most important driving forces for the automotive industry and for sheet metal forming are derived from three main factors: costumer demands that requires higher safety, more economical (low fuel consumption), more comfortable and more efficient vehicles. Legal requirements may be considered as the next important factor the, which aim the reduction of consumption and less harmful emissions. Finally, the global market competition, which leads to find a solution to meet all the mentioned requirements. Reduced consumption and less harmful emissions are also contradictory requirements at lower costs and with fast introduction into the everyday production. In order to ensure weight reduction, smaller sheet thickness should be applied, however, the requirement to increase safety is also in contradiction. The solution would be decreasing size, using high strength materials, what has unfavorable consequence, i.e. it would reduce formability [6].

In Figure 1, the energy requirements can be seen for combined city/highway driving. In the figure, they are accounted for as part of the engine and parasitic losses. 


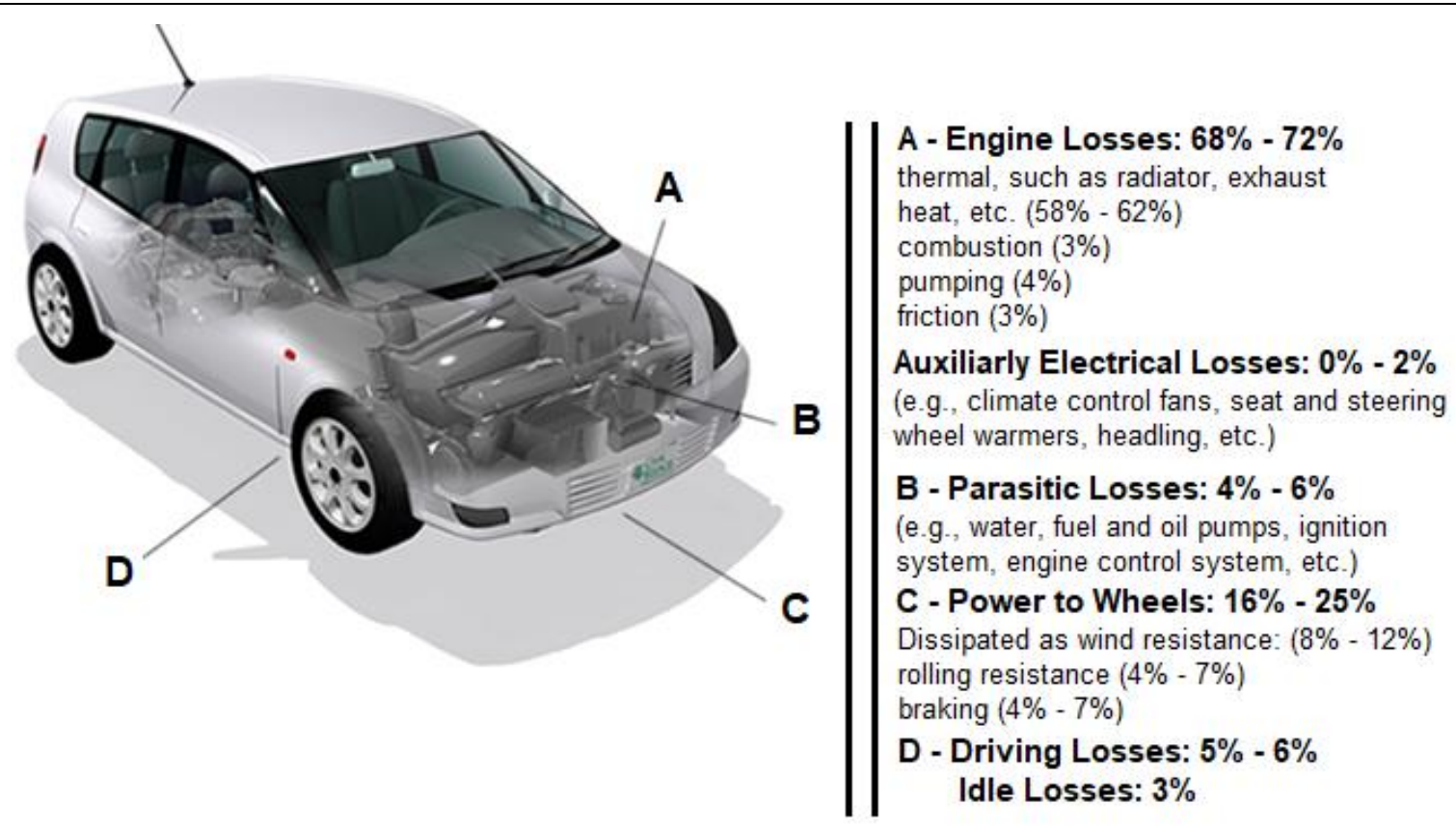

Figure 1 The energy requirements for combined city/highway driving [2]

\section{Direct $\mathrm{CO}_{2}$ emissions from light- and heavy-duty vehicles in the $\mathbf{E U}$}

The Figure 2 demonstrates important values and estimative related to $\mathrm{CO}_{2}$ emissions in the EU [3].

\section{Baseline 2030 Scenarios}

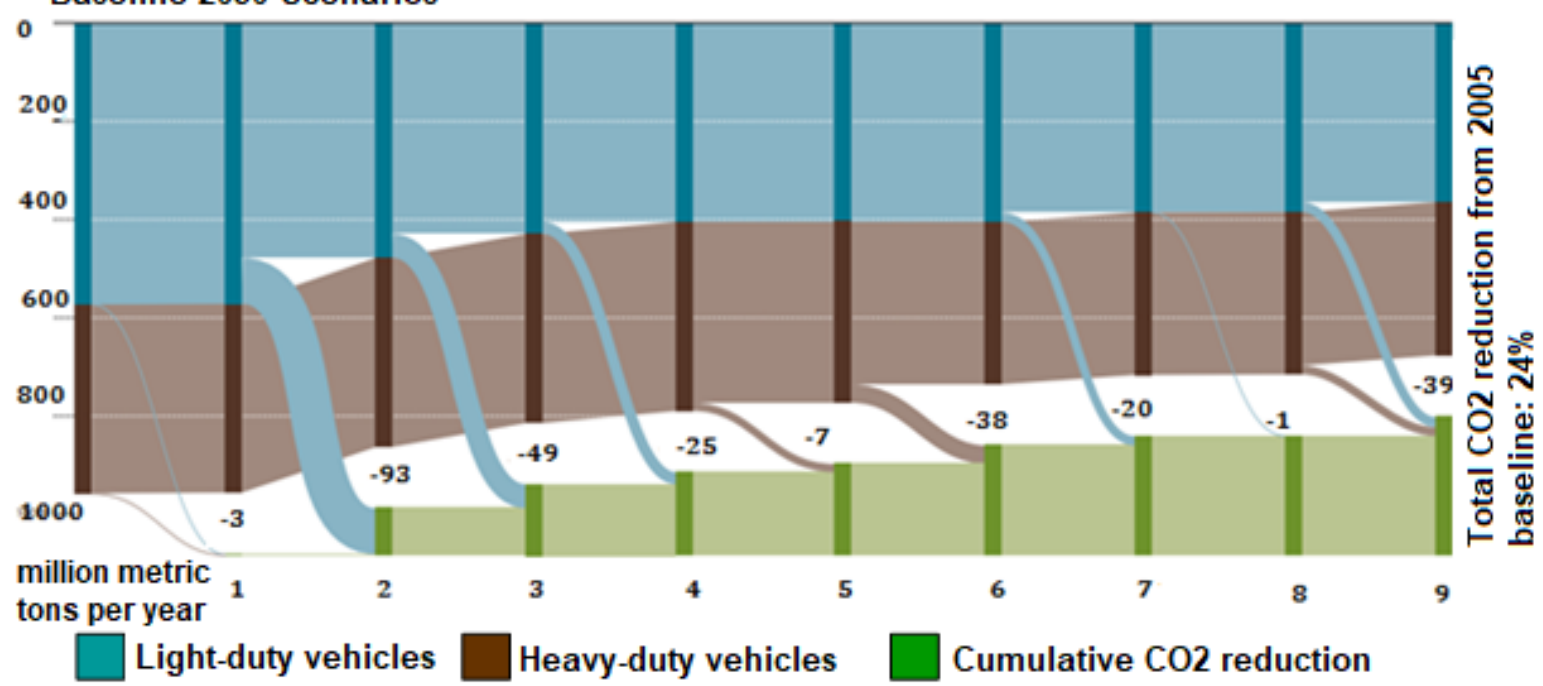

Figure 2 Values and estimative related to $\mathrm{CO}_{2}$ emissions in the EU [3]

$\mathrm{CO}_{2}$ targets according to New European Driving Cycle (NEDC) with equivalent reductions for light commercial vehicles. 
1. Incorporating road transport into the EU Emissions Trading Scheme (ETS)

2. Introducing a passenger car $\mathrm{CO} 2$ target of $78 \mathrm{~g} / \mathrm{km}$ for 2025 and $60 \mathrm{~g} / \mathrm{km} 2030$.

3. Introducing a passenger car CO2 target of $68 \mathrm{~g} / \mathrm{km}$ for 2025 and $42 \mathrm{~g} / \mathrm{km} 2030$.

4. Introducing a $15 \%$ non-to-exceed limit for real-world $\mathrm{CO}_{2}$ emissions

5. Introducing a heavy duty $\mathrm{CO}_{2}$ target by 2025

6. Introducing a heavy duty $\mathrm{CO}_{2}$ target by 2020

7. Increasing the market share of new electric vehicles to $23 \%$ by 2030

8. Increasing the share of biofuels

9. Increasing fuel taxes by 20 cents per litre.

In July 2012, the European Commission came forward with a regulatory proposal to set a 2020 target of $95 \mathrm{~g} / \mathrm{km}$ for newly registered vehicles. The regulation was formally adopted in March 2014 . It sets individual targets for manufacturers, depending on the average vehicle weight of a manufacturer's fleet, and requires all manufacturers to reduce $\mathrm{CO}_{2}$ emissions by $27 \%$ compared to their individual 2015 targets and the regulation will be phased in later, so that only in 2021 all vehicles will be taken into account [3].

\section{Vehicle Mass Distribution}

Several studies have examined the distribution of mass within typical vehicles. In Figure 3, the mass distribution in a passenger car (according to component groups) is shown a. From this distribution, it can be seen that the Body in White represents about $43 \%$ of the total vehicle mass as the heaviest group; followed by the powertrain and chassis, in almost equal proportions, at $27 \%$ and $26 \%$, respectively. More recently, it was also found that within the body group, the unit-body, or body-inwhite (BIW), is the single largest component, with about $28 \%$ of the total vehicle mass, while glass is $3 \%$, the interior $10 \%$ and $4 \%$ others [1].

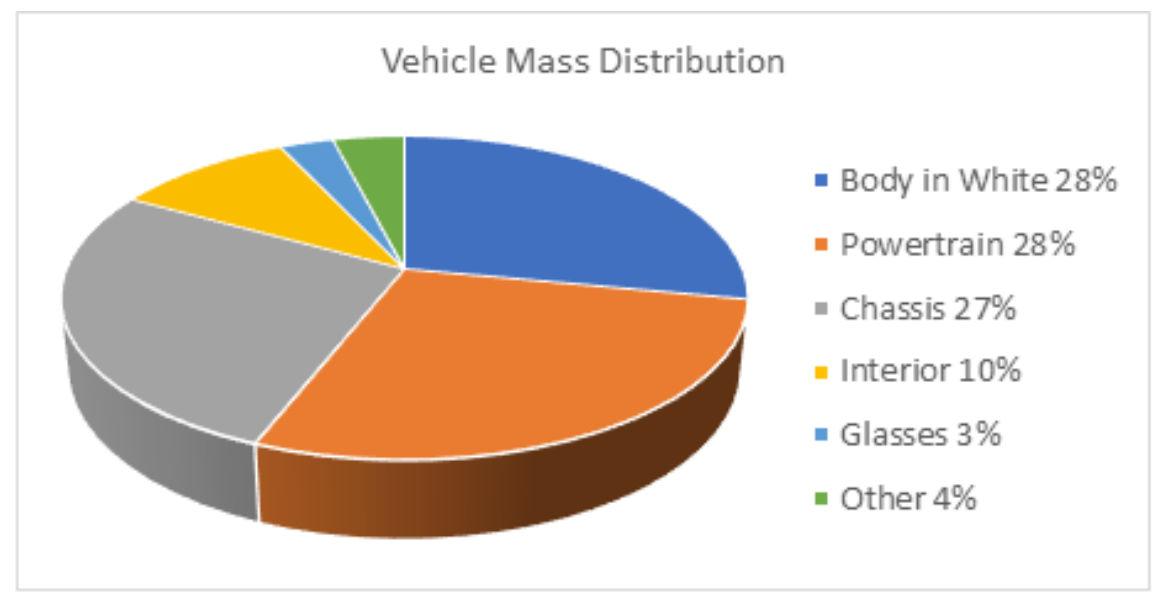

Figure 3 Vehicle mass distribution by subsystem (Bandivadekar, 2008) [5] 


\section{Vehicle Advanced Structural Materials}

The three main structural advanced material group for vehicle structural materials are: advanced high strength ferrous alloys, light metals (aluminum, magnesium and titanium) and non-metallic materials, e.g. composites and polymers.

Nowadays, among all important requirements mentioned before, the formability for new materials should be strongly considered in BIW (body in white) concept.

It is of great importance to find a good compromise between strength and formability properties, as using higher strength materials the formability usually decreases. The ultimate tensile strength and the total elongation has a hyperbolic relationship, i.e. lower strength with better formability and higher strength with lower formability. One of the main tendencies in the automotive industry is the application of light-weight design principles, what from the side of materials science, can be met by applying materials with high specific strength (UTS/ $\rho$ ) and high specific stiffness (E/ $\rho)$. Considering these properties, the application of high strength steels, light metals and alloys (particularly aluminum and magnesium), as well as an increasing amount of various non-metallic materials.

Recently, completely new generations of high strength steels were developed. These are called as Extra Advanced High Strength Steels (X-AHSS) and Ultra Advanced High Strength Steels (UAHSS).

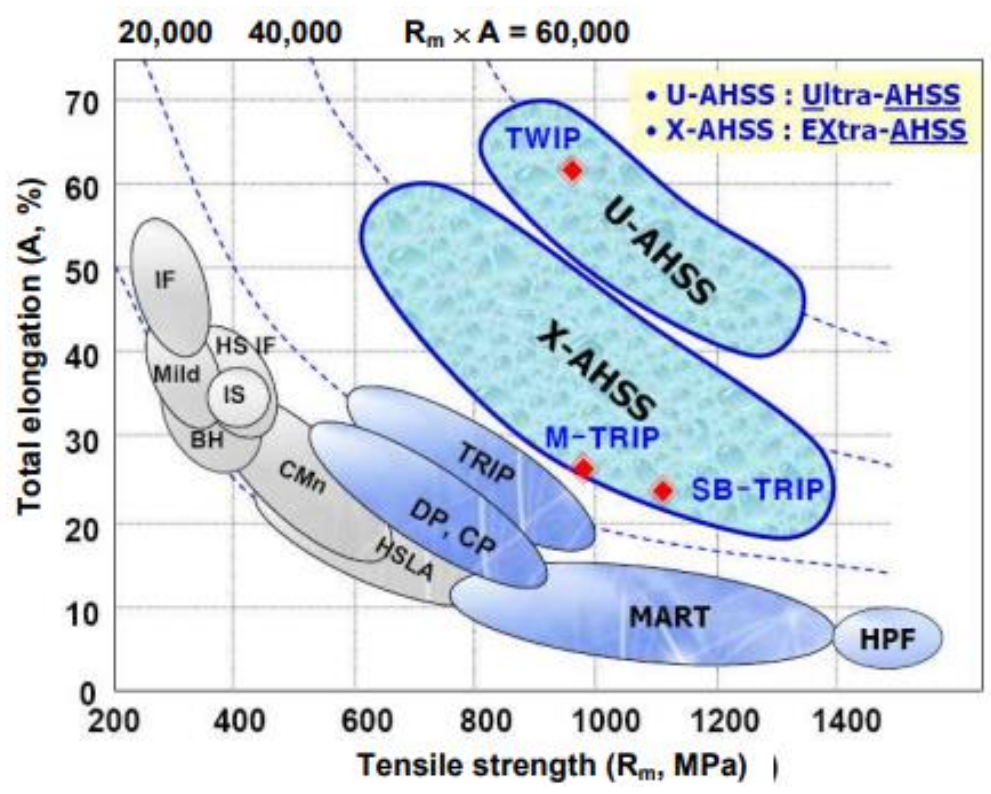

Figure 4 - Tensile strength vs. total elongation for X-AHSS and U-AHSS [5]

The product of the tensile strength and the total elongation for X-AHSS steels can be increased up to $C=40,000$ whilst for U-AHSS steels this hyperbolic constant can achieve even up to $C=60,000-$ 65,000. It means for example that at a given total elongation the tensile strength may be 3-4 times higher while the ductility may be the same or even higher than the value for conventional high strength steels shown in Figure 4. In Figure 4, these X-AHSS and U-AHSS steels are shown. The XAHSS steels may be regarded as the further developed version of TRIP steels. These extra-advanced and ultra-advanced high strength steels were first developed and applied in the automotive industry of the Far East automotive super powers, i.e. Japan and Korea. In the group of X-AHSS steels there are three main subgroups, namely: the FB-TRIP, SB-TRIP and the M-TRIP steels. The FB-TRIP steels 
have ferrite-bainitic microstructure and they are excellent in those applications where good stretchingflanging and hole expansion properties are expected. The SB-TRIP steels have nano-sized lamellar type, carbide-free bainite matrix with low amount of rest-austenite. Based on this microstructure, they are called as Super-Bainitic TRIP steels. They have extra high strength $\left(R_{m}=1600 \mathrm{MPa}\right)$ together with good formability (the total elongation is $A_{80}=27-30 \%$ ). The third subgroup, i.e. the M-TRIP steels can be found in the upper third range of X-AHSS steels. They got their name also reflecting their microstructure: there are some rest-austenite phases among small nano-sized, lamellar martensite matrix [5].

The U-AHSS steels can be found at the top edge of recent high strength steel developments. TWIP steels are one of the most excellent representatives of this group. The name Twinning Induced Plasticity reflects the main characteristics of deformation mechanism of this steel, i.e. a large number of twinning occur during plastic deformation. Due to the deformation twinning, this steel has extra high hardening capability with a great value of hardening exponent since during twinning the microstructure becomes finer and finer. The grain boundaries arising from the twinning deformation result in extreme high strength increase. TWIP steels thus can be characterized besides the extreme high strength with very large uniform elongation. Due to the high value of strain hardening exponent, it may achieve $n=0,4$ which leads to $50 \%$ uniform elongation and more than $65 \%$ total elongation. Thus, the $R_{m} \times A_{80}$ product can reach the constant value $C=65,000$ [5].

The application of non-ferrous (light metals) and non-metallic materials is one of the most evident solutions concerning the lightweight design principles in the automotive industry. Among light metals, the application of aluminum and magnesium alloys are in the forefront in car manufacturing.

Due to the increasing demand for environment-friendly vehicles requiring reduced fuel consumption and weight, besides steel as structural material, aluminum alloys in automobiles are recently also widely used in car manufacturing for body-in-white production, and their ratio will even further increase according to the application trends shown in [6].

\section{Body in White Concept (BIW)}

The Figure 5 shows a scope of stamped components for BIW components. Other metal components such as seat structures and hinges are not in scope.

Advanced engineering materials can play an important role in improving the efficiency of transportation engines and vehicles. Weight reduction targets are frequently set as a means to increase the fuel economy of vehicles, thereby reducing exhaust emissions. By reducing mass of the vehicle's main body and chassis structure, secondary weight and cost savings can be realized by downsizing subsystems through the mass decompounding effect. In addition, weight reduction has many significant secondary benefits; improving performance and handling dynamics. Lightweighting materials, including AHSS, aluminum, magnesium and titanium alloys, along with composites have significant potential to reduce BIW mass. 


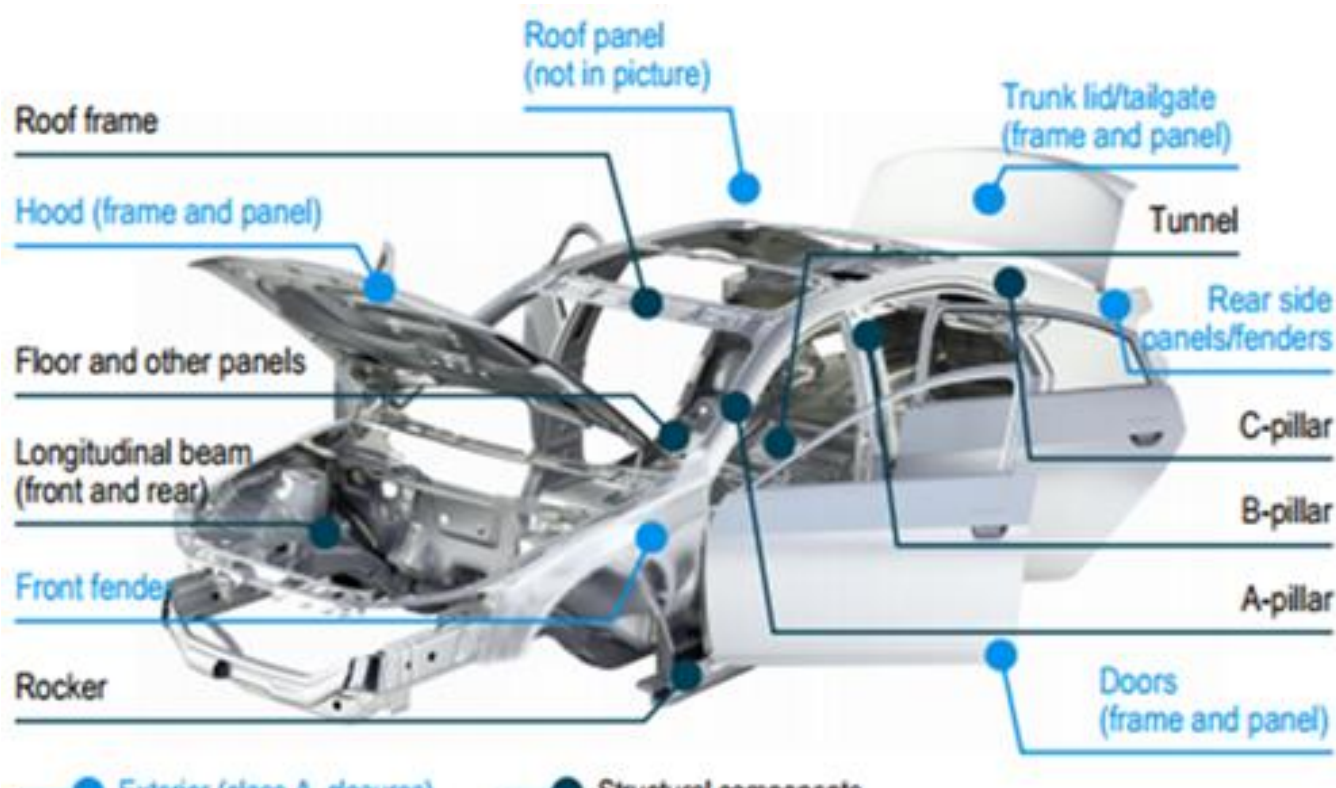

Exterior (class A dosures)

Structural components

Figure 5 Scope of stamped components for BIW [7]

\section{Hot forming for BIW components}

Hot forming is increasingly popular for BIW components - driven by increased strength and mass reduction requirements. Figure 6 shows a comparison of share of hot-stamped steel in BIW - Sample vehicles (\%) among a few models [7].

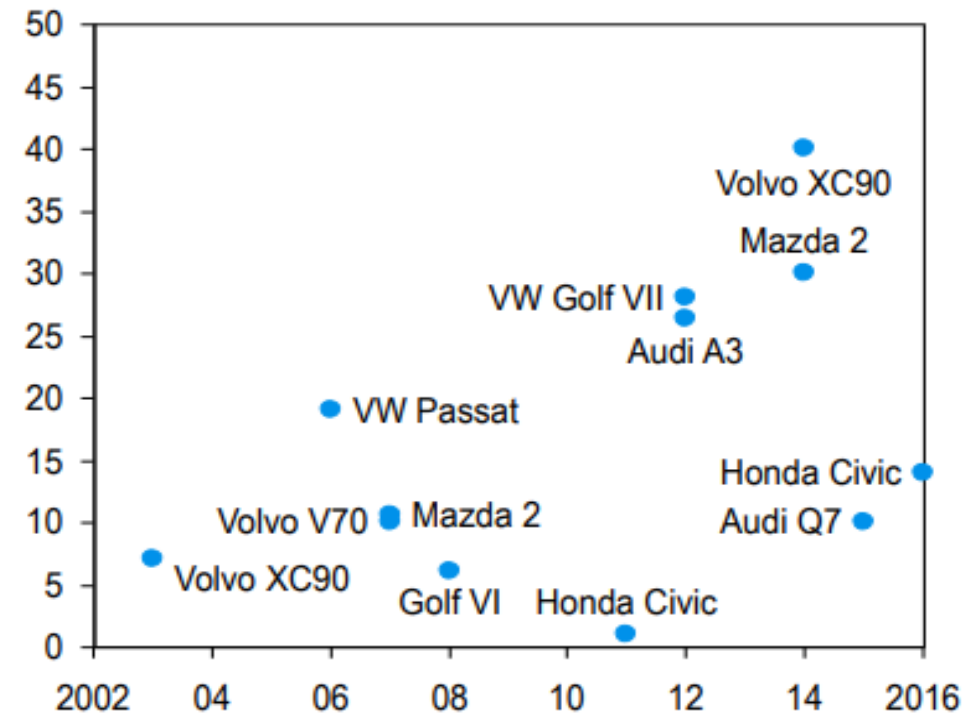

Figure 6 Share of hot-stamped steel in BIW-Sample vehicles (\%) [7]

Increasing share of hot-stamped steel in BIW is driven by certain beneficial attributes, including: 
- High strength and crash resistance at relatively low cost

- Low weight due to reduced material thickness

- Reduced spring-back during manufacturing process (common in cold-forming process)

- Best weight savings per additional cost compared to Aluminium and plastic composites

In addition, within specific models (Figure 7): e.g. In the Mazda 2, the current model has an approximate $30 \%$ share of hot-stamped steel, beating its predecessor model (approx. 10\%) - parts made of hot steel include A-pillar, roof frame, rocker panels [7].

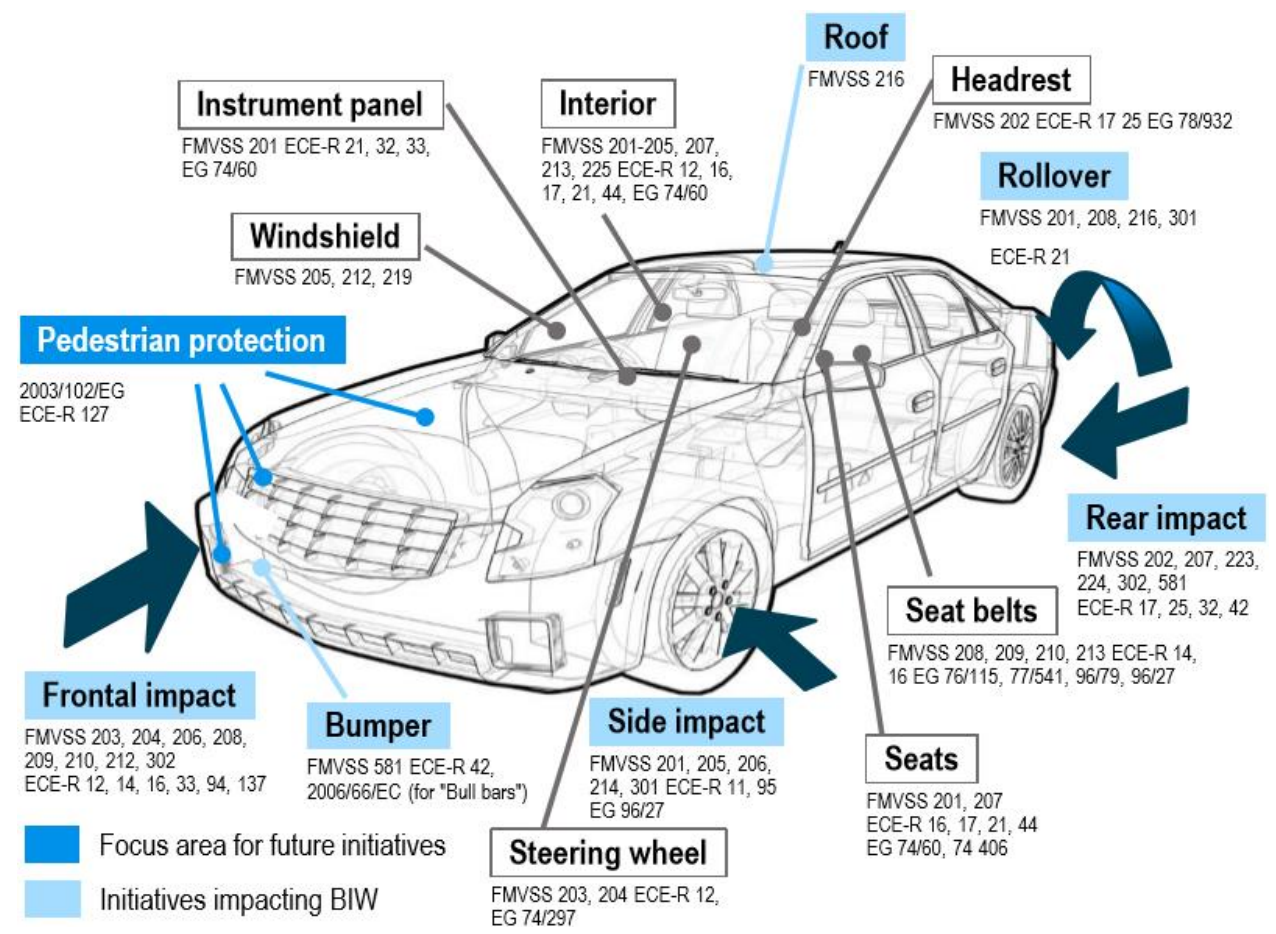

Figure 7 Crash regulations in Europe and US - Status as of 2016 [7]

Past initiatives to improve vehicle safety have already led to major changes in material use and BIW component design.

In Europe and the US, the market is driven by safety performance assessment programs such as Euro and US NCAP - Oms aim for top, 5-star ratings due to high customer awareness:

- In the past, Euro and US NCAP test requirements have focused on driver and passenger safety, with a high impact on BIW components - both material usage and component design were affected

- Future tests are expected to focus more on pedestrian safety and driver assistance programs

- This will not be majorly disruptive for BIW/chassis components, but

- New required functionalities will have to be integrated (e.g. "intelligent hoods")

- OEMs will be looking for materials that ensure a high level of design freedom, as design and specifications are impacted by the regulations. 


\section{Acknowledgements}

This research work started in the framework of TÁMOP-4.2.1.B-10/2/KONV-2010-0001 project and is continued in the project entitled Material Developments for the Automotive Industry within the project TÁMOP-4.2.2.A-11/1/KONV-2012-0029. Both projects are supported by the New Hungarian Development Plan and jointly financed by the European Union and European Social Fund.

\section{References}

[1] Bandivadekar, K., Bodek, L., Cheah, C., Evans, T., Groode, J., Heywood, E., Kasseris, M., Kromer, M., Weiss: On the Road in 2035: Reducing Transportation's Petroleum Consumption and GHG Emissions Laboratory for Energy and the Environment, Report No. LFEE 2008-05 RP, Massachusetts Institute of Technology, July, 2008

[2] The official U.S. government source for fuel economy information. Where the Energy Goes: Gasoline Vehicles, 2018

Available on: <https://www.fueleconomy.gov/feg/atv.shtml>

[3] European vehicle market statistics: Pocketbook 2016/2017. A statistical portrait of passenger car, light commercial and heavy-duty vehicle fleets in the European Union (EU) from 2001 to 2015.

Available on: 〈https://theicct.org/sites/default/files/publications/ICCT_Pocketbook_2016.pdf>

[4] NATC Engineering. Safety and comfort, 2020.

Available on: <https://natc-ht.com/engineering/engineering-2/>

[5] Tisza, M.: Recent development trends in sheet metal forming and Advanced Materials in Sheet Metal Forming Key Engineering Materials Vol. 581 (2014) pp 137-142 https://doi.org/10.4028/www.scientific.net/KEM.581.137

[6] Tisza, M., Czinege, I.: (2018) Aluminium alloys in automobiles, Comparative study of the application of steels and aluminium in lightweight production of automotive parts, International Journal of Lightweight Materials and Manufacture, p.4.

https://doi.org/10.1016/j.ijlmm.2018.09.001

[7] Automotive metal components for car bodies and chassis - 2016

Available on: <www.rolandberger.com> 